\title{
VEGETAÇÃO NATURAL POTENCIAL E MAPEAMENTO DA VEGETAÇÃO E USOS ATUAIS DAS TERRAS DA FLORESTA NACIONAL DE IPANEMA, IPERÓ/SP: CONSERVAÇÃO E GESTÃO AMBIENTAL
}

\author{
The potential natural vegetation and current land use mapping of Ipanema \\ National Forest, Iperó/SP: conservation and environmental management
}

\author{
Oriana Aparecida FÁVERO' \\ João Carlos NUCCl${ }^{2}$ \\ Mário de BIASI ${ }^{3}$
}

\begin{abstract}
Visando contribuir para o Plano de Gestão (Manejo) da Floresta RESUHMQ Ipanema (FLONA), o presente trabalho objetivou espacializar sua vegetação natural potencial e realizar o mapeamento da vegetação e usos atuais das terras, oferecendo subsídios básicos para seu planejamento ambiental. Para tanto, foi elaborado um croqui, espacializando a vegetação potencial da FLONA, utilizando: as descrições da paisagem de viagens de naturalistas (Saint-Hilaire, Spix e Martius) ao Brasil, no século XIX; estudos mais recentes sobre a vegetação da FLONA e a caracterização edáfica da área apresentada pela Carta de Solos da Fazenda Ipanema (escala 1:10.000). Com base na interpretação de fotos aéreas (escala 1:25.000 - Terrafoto, 1972) e verificações de campo, organizou-se o mapa de Vegetação e Usos Atuais das Terras (na escala 1:35.000). Considerando-se os conceitos de clímax climático e clímaces edáficos concluiuse que a vegetação potencial da FLONA seria de Floresta Estacional Semidecidual com manchas das diversas fisionomias de cerrado, limitadas em seu desenvolvimento pela ação do fogo, que no passado teria causas naturais.
\end{abstract}

\section{Palavras-chave:}

FLONA de Ipanema, unidade de conservação, vegetação potencial, usos das terras, plano de gestão.

\section{ABSTRACT}

Aiming at contributing to the management plan of the Ipanema National Forest, the present research set out to make a map of the potential natural vegetation and land current usage, offering basic aid to environmental planning. Moreover, a sketch-map was prepared, the potential FLONA vegetation, by means of: details of naturalist's trekking routes (SaintHilaire, Spix and Martius) in Brazil, in the nineteenth century; more recent studies of the FLONA vegetation; and the edaphic characterization of the area presented by the Soil Chart of Ipanema Farm (scale 1:10.000). Data were collected based on the interpretation of aerial photos (scale 1:25.000 Terrafoto, 1972) and site inspections, as well as the map of Vegetation and the Current Usage of the Land (scale $1: 35.000)$. Based on the concepts of climatic climax and edaphic climaxes it was concluded that FLONA potential vegetation would be a seasonal semi-deciduous forest with diverse semblances of scrub land, restricted in its development by fire acts, which in the past were natural causes.

\section{Key-words:}

Ipanema National Forest, protected area, potential vegetation, land uses, management plan.

1 UPMackenzie e USJT - bióloga, mestre e doutoranda em Geografia Humana do DG-USP. 2 Departamento de Geografia da UFPR - biólogo e doutor em Geografia Física - DG-USP.

3 Departamento de Geografia da FFLCH-USP - geógrafo e doutor em Geografia Humana - DG-USP. 
FÁVERO, O. A. et al. Vegetação natural potencial e mapeamento da vegetação...

\section{INTRODUÇÃO}

O desenvolvimento das atividades humanas vem provocando profundas modificações nos ambientes, enfraquecendo continuamente os sistemas naturais que asseguram a vida na Terra.

Desde a Revolução Industrial vive-se um modelo socioeconômico no qual a natureza deve ser transformada para dar lugar às obras humanas e gerar lucro direto e imediato. Neste sistema de valores não se cogita a importância da natureza como componente fundamental para a vida e nem mesmo o aproveitamento de seus serviços e benefícios para a satisfação das necessidades humanas fisiológicas e psicológicas.

Como uma das medidas de controle das enormes mudanças no uso e cobertura da terra, determina a Constituição Brasileira de 1988, em seu artigo 225, que é de competência do Poder Público, entre outras, a definição de Unidades de Conservação e entre elas estão as Florestas Nacionais.

As Florestas Nacionais (FLONAS) são Unidades de Conservação de Uso Sustentável (BRASIL, 2000) que apresentam como principais objetivos a promoção do manejo dos recursos naturais, com ênfase na produção de madeira e outros produtos vegetais, o desenvolvimento de atividades de recreação, lazer e turismo e a proteção de recursos hídricos, das belezas cênicas e dos sítios históricos e arqueológicos. O uso racional e sustentável das FLONAS far-se-á de acordo com o respectivo plano de manejo que, deverá conter programas de ação e de zoneamento ecológico-econômico.

O plano de manejo não se constitui em um conjunto de relatórios, mapas e tabelas, configurando-se em um acontecer unicamente técnico; ele forma um conjunto de diretrizes e deve exercitar-se segundo normas de lei já que "ninguém é obrigado a fazer ou deixar de fazer alguma coisa senão em virtude de lei" (BRASIL, 1988). Daí a importância de se considerar, com base no respeito à hierarquia das leis, as normas legais como, por exemplo, o Código florestal brasileiro e o Decreto 750/93, e as infralegais como as resoluções do CONAMA, - ConseIho Nacional do Meio Ambiente -,entre outras, na classificação e mapea-mento da cobertura vegetal.

Dentre os muitos elementos componentes das paisagens a vegetação e os usos das terras são destacados como primordiais e indispensáveis, tanto para entendimento da dinâmica das paisagens, quanto para orientar estratégias de planejamento considerando a melhoria da qualidade ambiental (GÓMEZ OREA, 1978; MCHARG, 1971; MONTEIRO, 2000; NUCCI, 2001).

Com o objetivo de subsidiar a confecção do Plano de Manejo/Gestão e o zoneamento ecológico-econômico, este trabalho elaborou a carta de Vegetação e Usos Atuais da Terra e, entendendo-se que o planejamento não trata somente da otimização de soluções para um período relativamente curto mas, também, da previsão e ordenamento das mudanças, propõe o conceito e mapeamento da vegetação potencial como uma meta a ser alcançada.

Salienta-se, também, que este trabalho considerou que "as descrições fisionômicas da vegetação constituem a fase inicial do estudo fitogeográfico enquanto que os dados florísticos é que vão decidir sobre as classificações fitogeográficas", como ensina RIZZINI (1963).

\section{CARACTERIZAÇÃO DA FLORESTA NACIONAL DE IPANEMA}

A Floresta Nacional de Ipanema (FLONA), instituída pelo Decreto № 530 de 20 de maio de 1992 , localiza-se entre as latitudes $23^{\circ} 25^{\prime}$ e $23^{\circ} 28^{\prime}$ Sul e as longitudes $47^{\circ} 33^{\prime}$ e $47^{\circ} 40^{\prime}$ Oeste, na região sudeste do Estado de São Paulo, distando cerca de 125km da capital Paulista e cerca de $20 \mathrm{~km}$ do centro de Sorocaba (o maior centro urbano nas proximidades), tendo como vias de acesso a saída 99-B da Rodovia Castelo Branco (SP280) e o km 112,5 da Rodovia Raposo Tavares (SP-270).

Possui 5.179,93 hectares (cerca de $50 \mathrm{~km}^{2}$ ) estando a maior parte de seu território na porção sul do município de Iperó (na Região Administrativa de Sorocaba), ficando uma pequena parte, a sudoeste, no município de Capela do Alto e outra, ao sul, no município de Araçoiaba da Serra (figura 01).

Sua área apresenta altitudes compreendidas entre 550 a 971 metros acima do nível do mar destacando-se a Serra de Araçoiaba, como característica singular ${ }^{1}$ na paisagem da região.

Dos contrafortes do Morro de Araçoiaba, hoje conhecido também por Morro de Ipanema, nasce o Rio Ipanema, afluente do Rio Sorocaba. Da parte central do mesmo Morro, surgem alguns riachos, dentre eles, o mais significativo é o Ribeirão do Ferro (afluente do Rio Ipanema), que nasce no Monte ou Pico do Chapéu e forma o Vale das Furnas com ocorrência de cascatas e piscinas naturais.

4 Segundo SANTOS (1952, p. 15 apud TAVARES, 1997, p. 32): "A silhueta do morro toma grande realce, por constituir relevo de exceção, [...] assemelha-se fisiograficamente a uma mesa irregular, com cerca de 8km, por 4 a $6 \mathrm{~km}$ de largura e $300 \mathrm{~m}$ de altura". 


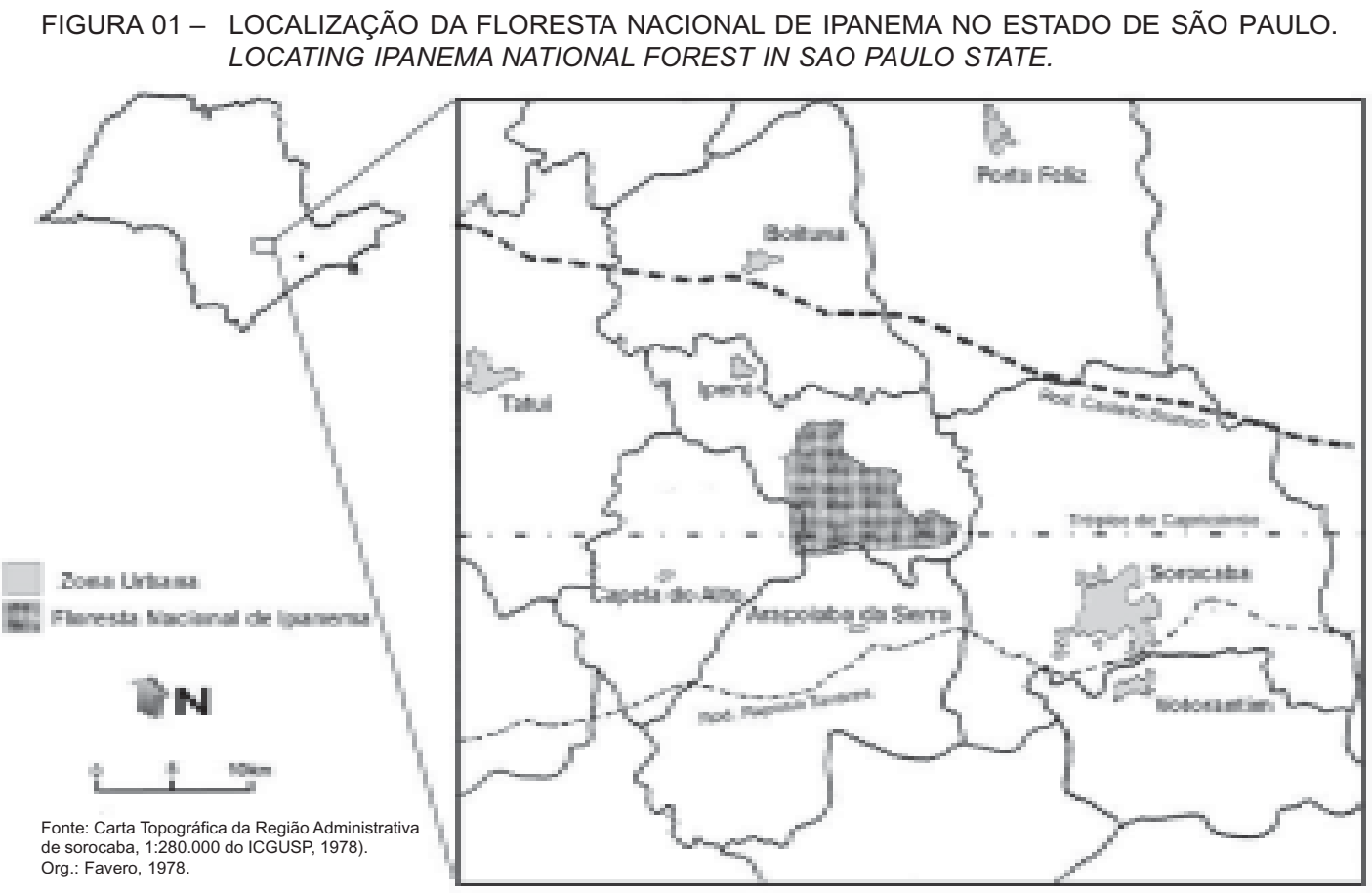

RANZANI et al. (1965) cartografou, na escala 1:10.000, 21 tipos diferentes de solos na FLONA de Ipanema, organizados em quatro grandes grupos predominantes:

- $\quad$ Latossolos vermelho escuro (2,5YR) originados de gnaisses e outras rochas metamórficas com contribuição de granitos (variedade amarela), são em geral profundos e com transição suave entre os horizontes; a textura geral é média e argilosa e a drenagem varia de moderada a boa; apresentam-se distribuídos em áreas de relevo ondulado e forte ondulado com maior ocorrência na Serra de Araçoiaba o que oferece limitações de uso sobretudo relativas a possibilidades de erosão do terreno e devidas a fertilidade do solo (distróficos); cobrem cerca de $23 \%$ da área da FLONA;

- $\quad$ Solos podzólicos amarelos (7,5YR) originam-se principalmente de arenitos, sendo em geral profundos e com transição suave entre os horizontes; a textura varia de média a arenosa com drenagem boa; distribuem-se em áreas de relevo ondulado movimentado (onde há riscos de erosão) e baixadas suavemente onduladas; a fertilidade é variável conforme o local; cobrem cerca de $22 \%$ da área da FLONA;

- Litossolos (associados a exposições rochosas) - a origem varia com o local; em geral são rasos (horizonte $A$ assentado sobre a rocha) com textura de média a arenosa e drenagem boa; há pedregosidade em vários locais e riscos de erosão; encontra-se sobretudo na Serra onde o relevo é mais movimentado e declivoso; cobrem cerca de $38 \%$ da área da FLONA (considerando também as exposições rochosas);

- Solos aluviais e hidromórficos - de origem fluvial, formado nas bacias de acumulação do quaternário ao longo dos rios; normalmente podem apresentar excesso de água; ocupam cerca de $15 \%$ da área da FLONA.

Utilizando o critério de classificação de Koeppen, SETZER (1944) afirmou que a FLONA de Ipanema encontra-se em uma faixa de transição climática entre o clima tipo Cfa (clima subtropical quente, o mês mais quente tem temperatura média superior a $22^{\circ} \mathrm{C}$ e o mês mais frio tem temperatura média inferior a $18^{\circ} \mathrm{C}$, constantemente úmido, com inverno menos seco; precipitação do mês mais seco entre 30 e $60 \mathrm{~mm}$ ) ao Sul e pelo clima Cwa (clima subtropical quente, com inverno mais seco; precipitação do mês mais seco menor que $30 \mathrm{~mm}$ ) ao Norte. 
FÁVERO, O. A. et al. Vegetação natural potencial e mapeamento da vegetação...

Porém, para ALBUQUERQUE (1999), a FLONA de Ipanema encontra-se submetida apenas ao clima Subtropical do tipo Cfa, mesotérmico úmido, sem estiagem, apresentando estações chuvosa e seca bem definidas (entre novembro e março e, entre abril e setembro, respectivamente), com precipitação anual de $1310 \mathrm{~mm}$, sendo janeiro o mês mais chuvoso $(233 \mathrm{~mm})$ e mais quente $\left(24,2^{\circ} \mathrm{C}\right)$, agosto o mês mais seco (33mm) e julho o mês mais frio $\left(1,4^{\circ} \mathrm{C}\right)$, notando-se uma coincidência entre as estações térmicas e úmida e seca.

Com base em MONTEIRO (1973), constata-se que a FLONA de Ipanema está localizada em uma zona de transição entre climas controlados por massas tropicais e polares (climas úmidos da face oriental e subtropical dos continentes dominado por massa Tropical Marítima - $\mathrm{mT}$ ) e climas controlados por massas equatoriais e tropicais (climas tropicais alternadamente secos e úmidos).

Segundo o Mapa de Vegetação do Brasil, na escala 1:5.000.000 (BRASIL, 1993), a FLONA de Ipanema está localizada em uma Área de Tensão Ecológica com contatos entre Savana e Floresta Ombrófila. Este tipo de ecótono (mistura florística entre tipos de vegetação), com estruturas fisionômicas diferentes, permite a delimitação dos mosaicos por simples fotointerpretação.

Entretanto, ALBUQUERQUE (1999), em estudo fitossociológico no Morro de Araçoiaba (FLONA de Ipanema), encontrou, além de espécies características de Floresta Estacional Semidecidual, espécies pertencentes à outros tipos de formações como Floresta Ombrófila Mista, Cerrado senso lato, Floresta Ombrófila Densa e afirmou, com base em seu levantamento florístico, que a FLONA de Ipanema possui uma condição ecotonal onde a matriz é Floresta Estacional Semidecidual com exemplares de florestas Ombrófila Densa e Mista e de Cerrado senso lato.

ALBUQUERQUE (1999), ainda coloca que o Morro de Araçoiaba possui uma floresta jovem, sendo a maioria dos seus indivíduos de tamanho pequeno ou estando em fase de crescimento, mas afirma que a FLONA de Ipanema

(...) constitui-se num dos poucos redutos florestais do interior paulista e que apesar do histórico de perturbação é a maior área contínua florestada da região administrativa de Sorocaba, com muitos ambientes distintos e certamente a maior detentora da biodiversidade regional.

A fauna da FLONA de Ipanema é bastante diversificada contando com várias espécies de mamíferos como o cachorro-do-mato, o jaguarundi, o veado-catingueiro, o quati, etc. (MICHALSKI, 2000), aves como o urubu-rei, a garça, e o pavó, pássaro ameaçado de extinção segundo REGALADO (1999), répteis (jararaca, teiú, etc..), anfíbios (rã-manteiga) e inúmeros invertebrados.

A área da FLONA de Ipanema desde o século $\mathrm{XVI}$ vem passando por diferentes tipos de exploração: mineral (ferro, calcário e fosfatos), agrícola, pecuária,

TABELA 1 - USOS ATUAIS NA FLORESTA NACIONAL DE IPANEMA. PRESENT USES OF IPANEMA NATIONAL FOREST.

\begin{tabular}{|c|c|c|}
\hline Usos & $\begin{array}{c}\text { ALBUQUERQUE } \\
(1999)^{*}\end{array}$ & $\begin{array}{l}\text { FÁVERO } \\
(2001)^{*}\end{array}$ \\
\hline Reflorestamento com Eucalyptus spp. Eucalyptus spp reforestation. & 171,5 ha $(3,4 \%)$ & $\begin{array}{c}220,0 \text { ha } \\
(4,0 \%)\end{array}$ \\
\hline $\begin{array}{l}1 \text { - Vegetação natural secundária no Morro de Araçoiaba. Natural } \\
\text { secondary vegetation in Araçoiaba Mount } \\
2 \text { - Cobertura florestal secundária. Secondary forest cover. }\end{array}$ & $\begin{array}{c}1.388,0 \text { ha } \\
(27,4 \%)\end{array}$ & $\begin{array}{l}1.388,0 \text { ha } \\
(27,0 \%)\end{array}$ \\
\hline $\begin{array}{l}\text { Várzea, açudes e represas. Meadow, dams and hydroelectrical } \\
\text { dams. }\end{array}$ & 250,0 ha $(4,9 \%)$ & --- \\
\hline Capoeira baixa. Low "capoeira" bush. & 650,0 ha $(12,8 \%)$ & --- \\
\hline Capoeira alta (grotões). High "capoeira” bush. & $1.067,0$ ha $(21,0 \%)$ & --- \\
\hline Cerrado senso lato. Meadow. & 308,06 ha $(6,1 \%)$ & --- \\
\hline $\begin{array}{l}1 \text { - Área destacada para fins de assentamento. Spotted areas. } \\
2 \text { - Movimento dos Sem Terra - MST. Landless. }\end{array}$ & $\begin{array}{c}1.185,17 \text { ha } \\
(23,4 \%)\end{array}$ & $\begin{array}{c}1.148,0 \text { ha } \\
(23,0 \%)\end{array}$ \\
\hline $\begin{array}{l}\text { Sede administrativa, vilas, residências e sítios históricos. } \\
\text { Administrative headquarters, villas, dwellings and historical sites. }\end{array}$ & 50,0 ha $(1,0 \%)$ & $\begin{array}{l}50,0 \text { ha } \\
(1,0 \%)\end{array}$ \\
\hline $\begin{array}{l}\text { Vegetação herbácea pioneira, capoeiras, várzeas e cerrado. Pioneer } \\
\text { herb vegetation, "capoeiras" and meadow. }\end{array}$ & --- & $\begin{array}{l}2.300,0 \text { ha } \\
(45,0 \%)\end{array}$ \\
\hline TOTAIS & $5.069,73$ ha & $5.106,00 \mathrm{ha}$ \\
\hline
\end{tabular}

* SEGUNDO COMUNICAÇÃO PESSOAL COM A CHEFE DA FLONA DRA. OFÉLIA DE FÁTIMA GIL WILLMERSDORF. 
testes com máquinas voltadas para a agricultura (tratores, aviões, etc.). Atualmente o uso da terra na FLONA de Ipanema está dividido da seguinte forma:

A FLONA de Ipanema corresponde a uma Unidade de Conservação de Uso Sustentável, conforme - Sistema Nacional de Unidades de Conservação do Brasil - SNUC (Lei no. 9.985 de 18/07/2000, Cap.I, Art. $2^{\circ}$, inciso $\mathrm{XI}$ ) e está sob administração do IBAMA Instituto Brasileiro de Meio Ambiente e dos Recursos Naturais Renováveis; apresenta locais de grande importância histórica (monumentos da primeira siderúrgica brasileira), e é recoberta por um dos principais remanescentes de Mata Atlântica do interior do Estado de São Paulo. Está próxima aos centros urbanos mais desenvolvidos deste Estado representando, portanto, um ponto de refúgio de fácil acesso a visitantes além de apresentar grande potencial para ecoturismo.

\section{MATERIAIS E MÉTODOS}

Para organizar o mapa de Vegetação e Usos Atuais das Terras, na escala 1:35.000, foram seguidos os seguintes passos:

- $\quad$ primeiramente a organização da carta topográfica 1:35.000 oriunda da redução de 5 cartas topográficas na escala 1:10.000 do IGC de 1978 (folhas SF-23-Y-C-I-4-SO-B/ SO-D/SE-A/SE-C/SE-D); esta base topográfica apresenta informações de referência no território (todos os rios; as principais estradas, caminhos, vilas/povoados e edificações; entre outros elementos) e as principais curvas de nível correspondendo à eqüidistância de $50 \mathrm{~m}$;

- $\quad$ em seguida utilizou-se o procedimento de interpretação das fotos aéreas (oito pares estereoscópios, em preto e branco, na escala 1:25.000, do aero-recobrimento realizado pela Terrafoto em 1972), obtidas com o IBAMA; a interpretação das aerofotografias foi realizada com a utilização de estereos-copia, que permitiu a identificação da fisiono-mia da cobertura vegetal e outros alvos, considerando diferenças de tonalidades de cinza, forma, textura, padrão, sombra, tama-nho e adjacências;

- $\quad$ as informações originadas da fotointerpretação foram transcritas para a base topográfica utilizando pontos comuns entre fotos e carta, controlando distorções por meio da realização das correções dentro de triângulos de pequena área, tomando-se três pontos de referência bem visíveis;

- $\quad$ por fim foram realizadas sete expedições à FLONA nas quais procurou-se observar diretamente suas características, ora explorando os mais diversos acessos (estra-das, trilhas, caminhos, etc.), ora aproveitando mirantes e locais mais altos (utilizando binóculos), para verificação in situ das informações da carta topográfica e da fotointerpretação, complementando-as, corrigindo-as e documentando-as (principalmente por meio de registro escrito, cartográfico e fotográfico).

Por se tratar de um mapa de vegetação que tem como objetivo subsidiar o planejamento da UC, a escolha das categorias para a legenda procurou levar em consideração as informações do Mapa de Vegetação do Brasil, na escala 1:5.000.000 (BRASIL, 1993), do Manual Técnico da Vegetação Brasileira (BRASIL, 1992), do trabalho de ALBUQUERQUE (1999), das disposições do Decreto Federal $n^{\circ} \cdot 750 / 93^{5}$ e da Resolução CONAMA n. ${ }^{\circ} 001$ de 31/01/1994, adaptadas aos termos mais utilizados pela comunidade local, que são semelhantes aos encontrados no Inventário Florestal do Estado de São Paulo (SMA/CINP/IF, 1993).

Já para a elaboração do croqui da vegetação potencial da FLONA, utilizou-se:

- do resgate e da formulação de um conceito para "vegetação potencial" com base em estudos de dinâmica de paisagens, sucessão natural e conceitos de clímax climático e edáfico;

- $\quad$ as descrições das paisagens feitas por naturalistas que passaram pelo região no século XIX, como Saint-Hilaire, Spix e Martius;

- de estudos fitogeográficos sobre o Estado de São Paulo (HUECK, 1956; TROPPMAIR, 1969; EITEN, 1970 E VICTOR, 1975);

5 O Decreto no. 750/93 regulamenta a exploração dos remanescentes de Mata Atlântica dispondo sobre o corte, a exploração e a supressão de vegetação primária ou nos estágios avançado e médio de regeneração, de tal forma que esta vegetação, nestas condições, estão protegidas. 
FÁVERO, O. A. et al. Vegetação natural potencial e mapeamento da vegetação...

- do estudo fitossociológico no Morro de Araçoiaba (ALBUQUERQUE, 1999);

- a caracterização edáfica da área apresentada pela Carta de Solos da Fazenda Ipanema na escala 1:10.000 (RANZANI et al., 1965), e

- da própria Carta de Vegetação e Usos Atuais da Terras da FLONA de Ipanema.

\section{RESULTADOS E DISCUSSÃO}

\section{SITUAÇÃO ATUAL}

Na seqüência são apresentadas, de modo detaIhado, as categorias adotadas para legendar o Mapa da Vegetação e de Usos Atuais. Vale ressaltar que os limites entre as categorias, sobretudo de vegetação, são passíveis de revisão devido a antigüidade do levantamento foto-aéreo e da presença de áreas de contato entre tipos de vegetação com estruturas fisionômicas semelhantes (ecótonos). Há também áreas para as quais foram utilizadas categorias "híbridas", por exemplo capoeira+campo+brejo, pois não foi possível espacializar as manchas de cada fisionomia, ou devido ao pequeno tamanho ou ainda estarem muito entremeadas, inviabilizando a representação na escala adotada. As categorias de vegetação (Mata, Capoeira e Campo) pertencem ao "sistema secundário" (BRASIL, 1992), ou seja, estão em áreas onde houve intervenção humana para uso da terra (mineração, agricultura, pecuária, etc.) com descaracterização da vegetação primária. A quantificação em termos de porcentagem relativa acompanha cada item da legenda que se apresenta a seguir:

- $\quad$ Mata $(35,7 \%)$ - Floresta nos estágios de médio a avançado de regeneração (BRASIL, 1994), ou entre a fase de sucessão conhecida por "capoeira propriamente dita" e a fase de "capoeirão" (VELOSO, 1945 apud BRASIL, 1992); com predominância de árvores formando um dossel que oferece maior dificuldade à passagem da luz de tal forma que o estrato herbáceo é menos desenvolvido; a altura média das árvores varia bastante ocorrendo locais (principalmente sobre a serra) nos quais pode ultrapassar $20 \mathrm{~m}$ e onde ocorrem indivíduos com grande espessura do tronco.

- Capoeira (16,9\%) - Floresta nos estágios de inicial a médio de regeneração (BRASIL, 1994), ou entre a fase de sucessão conhecida por "capoeira rala" e a fase de "capoeira propriamente dita" (VELOSO, 1945 apud BRASIL, 1992) caracterizada por um dossel descontínuo que permite maior passagem de luz havendo, portanto, o desenvolvimento de algumas herbáceas; a altura do dossel é variável podendo atingir $15 \mathrm{~m}$; aparece também ao longo dos rios em vários locais como formação substituta da mata ciliar.

- Campo (11,0\%) - formação vegetal com predominância de herbáceas pioneiras; na FLONA ocorrem entremeados os "limpos", que caracterizam-se por baixa ocorrência de arbustos e/ou arvoretas, e os "sujos", nos quais a freqüência de arbustos e arvoretas é maior ("capoerinha" segundo VELOSO, 1945 apud BRASIL, 1992); em geral predominam espécies invasoras como o capim-gordura, o colonião e a vassourabranca; há variação na predominância de gramíneas e em sua altura $(20-30 \mathrm{~cm}$ até $2 \mathrm{~m})$.

- Capoeira+Campo+Brejo (7,2\%) categoria "híbrida", de formação vegetal, na qual ocorrem as três formações respectivamente, em manchas não cartografáveis na escala adotada e/ou muito entremeadas; o brejo se constitui em uma formação vegetal na qual predominam espécies herbáceas higrófilas e/ou aquáticas; ocorre próximo ou na beira dos rios e represas em terreno encharcado/submerso com predominância de solos que oferecem dificuldade para a drenagem (aluvial e hidromórfico).

- Cerrado Sensu Strictu (1,0\%) - formação vegetal savânica na qual as árvores e arbustos são "nanicos" (altura de 1 a $5 \mathrm{~m}$ ) e apresentam galhos tortuosos com casca grossa, folhas grandes, coriáceas, envernizadas ou revestidas por pêlos; é encontrado em pequeno trecho no SE da FLONA.

- Reflorestamentos e Áreas Cultivadas (5,7\%) - áreas com vegetação plantada do tipo florestal como os Eucalyptus e Pinus, ou do tipo perene como o pomar, ou ainda para produção de mudas como os viveiros.

- Cultivos Diversos+Pasto+Campo (21,5\%) - categoria "híbrida", de uso e ocupação da terra, na qual encontramos áreas cultivadas com culturas anuais e perenes, e áreas de pastagens com gramíneas entremeadas com 
vegetação de campo, sobretudo na área ocupada pela população do MST que desenvolve estas atividades.

- $\quad$ Área de Uso Múltiplo $(1,0 \%)$ - próxima à Represa Ipanema (Hedberg) ocorrem a Vila São João do Ipanema com ruas pavimentadas e moradias para a família do pessoal administrativo, com jardins nas casas, campo de futebol e quadra esportiva, praça central ajardinada, arborização com espécies exóticas, prédios administrativos e alojamentos do IBAMA, e sítio histórico da primeira siderúrgica brasileira.

O Mapa Topográfico (figura 02) acompanha o Mapa da Vegetação e de Usos Atuais (figura 03), com o intuito de facilitar a localização das manchas ao fornecer pontos de referências.

\section{O CONCEITO DE VEGETAÇÃO NATURAL POTENCIAL}

As medidas para a conservação dos recursos naturais são, na maioria das vezes, baseadas no diagnóstico do valor atual desses recursos, não se levando em consideração a situação futura a curto, médio e a longo prazo.

Pode-se citar como exemplo de medida para a conservação da natureza que se pauta apenas pela avaliação da situação atual, os mecanismos legais que orientam os procedimentos de licenciamento de exploração da vegetação nativa do Estado de São Paulo e que proíbem o corte, a exploração e a supressão de vegetação primária ou nos estágios avançados e médio de regeneração da Mata Atlântica (Decreto $\mathrm{n}^{\circ} 750$ de 10/02/1993, artigo $1^{\circ}$ ), com as definições de vegetação primária e secundária nos estágios pioneiro, inicial, médio e avançado de regeneração, informadas pela Resolução CONAMA n ${ }^{\circ} 001$ de 31/01/1994.

Por não considerarem a sucessão natural da vegetação, ou seja, a situação futura, esses instrumentos legais desvalorizam a vegetação secundária nos estágios pioneiro e inicial de regeneração, mesmo que elas com o passar do tempo venham a se constituir em vegetação de estágios médio e avançado, passando, assim, para a proteção da lei.

Constata-se, também, na população em geral e até entre pessoas do meio (estudantes e técnicos) um certo desprezo para com a vegetação classificada pelos pesquisadores como secundária, entendendo-se, portanto, como de baixo valor para conservação. É preciso ensinar que, praticamente, não há vegetação primária no Brasil e no Mundo, principalmente nas áreas que passaram por surtos de desenvolvimento econô-mico, e que apesar de em muitos casos a vegetação apresentar dificuldades para a sua regeneração, isso pode acontecer naturalmente ou com a ajuda do ser humano.

Dentro desse escopo, constatando-se a falta de instrumentos de valorização da vegetação futura, é que se sugere a utilização do conceito e o mapeamento da vegetação natural potencial.

Segundo NAVEH \& LIEBERMAN (1883), o termo potential natural vegetation foi sugerido por TÜXEN (1956) sendo, também, utilizado pelo biogeógrafo Schmithüsen como potential e Naturlandschaft (paisagem natural potencial) e por KUCHLER $(1967,1975)$ na América do Norte, significando uma abstração conceitual ao sugerir a construção da vegetação que poderia vir a se estabelecer se o ser humano desapa-recesse subitamente; baseia-se no conhecimento cor-rente da vegetação atual, suas tendências de desen-volvimento e relações locais; o mapeamento da vege-tação natural potencial, executados e em andamento na Alemanha, tem produzido importantes informações para o planejamento e gestão da paisagem.

A caracterização da vegetação potencial surge, portanto, como resultado de um exercício de encadeamento causal que permite uma previsão dos efeitos com base no conhecimento das causas, ou seja, pretende-se realizar um diagnóstico da situação futura (prognose, prognóstico ou previsão), como auxílio fundamental para o planejamento. Leva-se em conta as possibilidades de evolução a médio e a longo prazo, considerando-se, assim, a vegetação potencial um importante conceito para a conservação da natureza já que, segundo GÓMEZ OREA (1978) para se decidir sobre o interesse de um território com vistas a sua conservação, deve-se ter em conta seu valor dentro de $1,10,100$ ou mais anos e que no caso da vegetação caberia predizer sua evolução natural.

O conceito de vegetação potencial está intimamente relacionado ao conceito de clímax e à valorização das paisagens levando-se em consideração sua evolução no tempo e no espaço.

Segundo BERTRAND (1972) a paisagem (geossistema $)^{6}$ encontra-se em estado clímax quando há um 


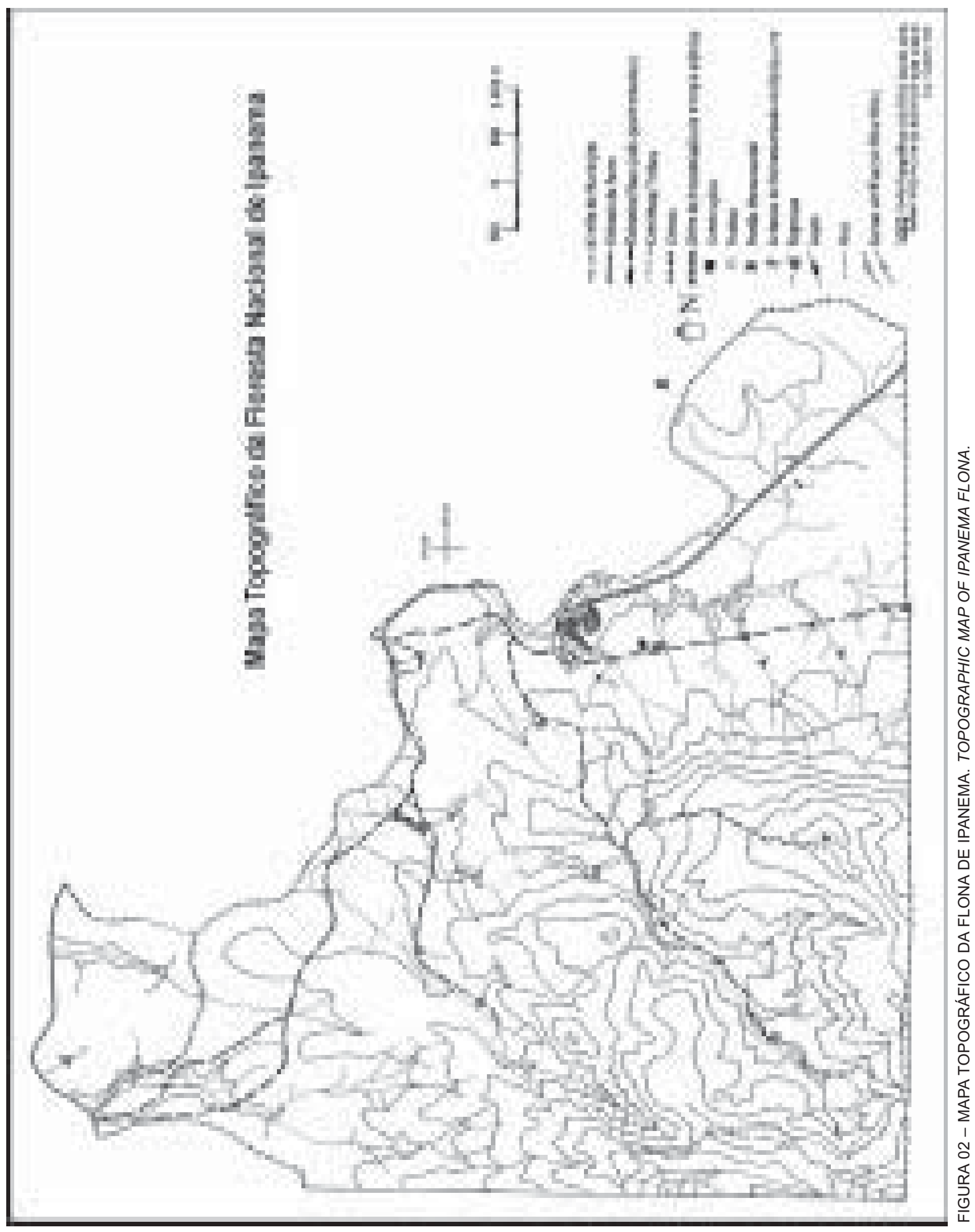




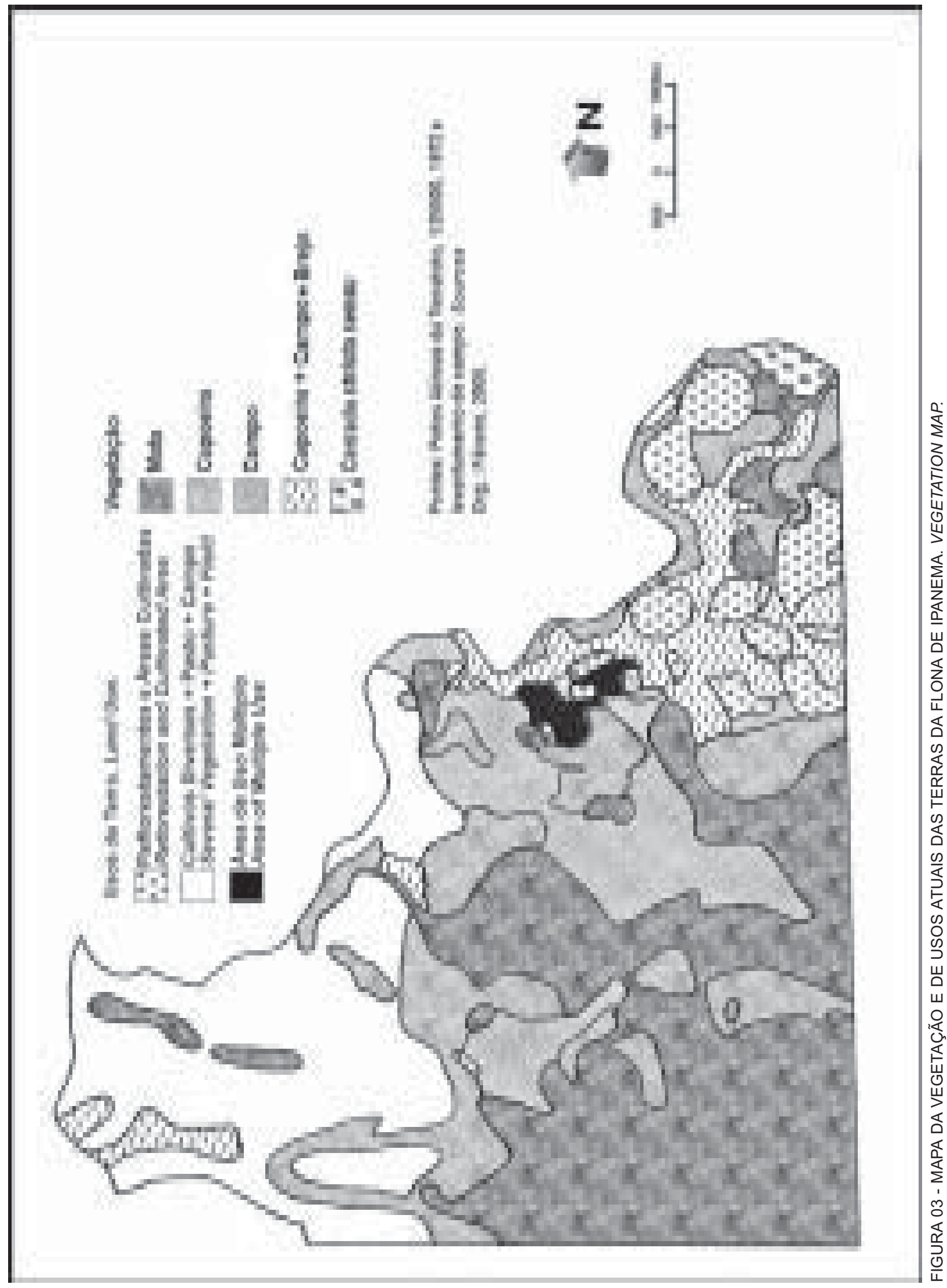


FÁVERO, O. A. et al. Vegetação natural potencial e mapeamento da vegetação...

equilíbrio entre o potencial ecológico (clima-hidrologiageomorfologia) e a exploração biológica (vegetaçãosolo-fauna); para ele o clímax seria o estágio final da evolução do geossistema. Verifica-se a valorização da evolução no tempo, quando o mesmo autor sugere a classificação dinâmica dos diferentes tipos de paisagens, levando-se em consideração três elementos básicos: o sistema de evolução, o estágio atingido em relação ao clímax e o sentido geral da dinâmica (progressão, regressão ou estabilidade).

Para ODUM (1983), clímax seria a comunidade final ou estável numa série desenvolvimental (sere) e considera que, para uma dada região, haveria o reconhecimento de um único clímax regional ou climático, em equilíbrio com o clima geral e um número variável de clímaces locais ou edáficos, pois, entende-se que, apesar de qualquer região possuir um clímax climático teórico, seria improvável que todas as comunidades de uma dada região climática terminem iguais.

Pode-se, ainda, definir clímax climático como a vegetação que se encontra equilibrada dentro do clima regional, como por exemplo, Floresta Ombrófila Densa Amazônica e Atlântica, Caatinga do sertão árido nordestino e outros, e clímax edáfico a vegetação que se encontra equilibrada dentro de uma situação pedológica uniforme regionalmente, como por exemplo, Campinarana que ocupa as áreas de Podzol Hidromórfico e Areias Quartzosas Hidromórficas na bacia do alto rio Negro e de Savanas (Cerrado) que revestem áreas de solos degradados e aluminizados (BRASIL, 1992).

Segundo BERTRAND (1972), o clímax está longe de ser sempre realizado, pois o potencial ecológico e a ocupação biológica são dados instáveis que variam tanto no tempo quanto no espaço, fazendo com que o geossistema seja um complexo essencialmente dinâmico.

AB'SABER (1967), ao esclarecer o conceito de feições mistas (faixas ou áreas de transição) na classificação dos Domínios Morfoclimáticos Brasileiros, afirma que somente as áreas core dos domínios ou conjuntos regionais de paisagens têm individualidade plena, sendo as únicas áreas dotadas de setores regionais de vegetação, passíveis de serem tomadas, sem nenhuma duvida, como áreas clímax, do ponto de vista rigorosamente fitogeográfico.

A caracterização da vegetação clímax pode contar com o auxílio do levantamento da cobertura tal como deveria ter sido antes da intervenção humana, ou seja, a "vegetação original" (HUECK, 1956) ou "vegetação primitiva” (TROPPMAIR, 1969). Porém, deve-se tomar o cuidado para não confundi-las com a vegetação natural potencial que nem sempre é equivalente à cobertura vegetal do passado, devido aos fatores limitantes que podem se modificar com o passar do tempo.

Além desse método, para se caracterizar a vegetação potencial pode-se utilizar a comparação com base em observações das diversas unidades de paisagem que se encontram próximas à área estudada e que se apresentam em diferentes estágios de desenvolvimento. A análise de fotografias aéreas de diferentes épocas, também, se constitui em um excelente meio para o estudo da dinâmica de paisagens e, portanto, para a configuração da vegetação natural potencial.

Apesar de todas as dificuldades existentes na execução de exercícios de previsão, julga-se imprescindível o diagnóstico da situação futura das paisagens (prognose), como uma das etapas do processo de planejamento para fins de conservação da natureza.

Para a vegetação, como parte integrante dessa paisagem futura, considera-se "vegetação natural potencial" a máxima expressão que a vegetação atingiria se tivesse a liberdade de se desenvolver sem a interferência do ser humano, considerando-se os atuais limites dados pelo clima e pelas condições edáficas.

\section{VEGETAÇÃO NATURAL POTENCIAL DA FLONA DE IPANEMA}

O resgate parcial das descrições das paisagens feitas por naturalistas que visitaram a região da Fazenda Ipanema nas primeiras décadas do século XIX, a consulta aos trabalhos e reconstituição da vegetação primitiva do Estado de São Paulo, bem como aos trabalhos de levantamento da vegetação atual e a consideração das características do clima e dos solos da região, serviram de base para a caracterização da vegetação potencial da FLONA de Ipanema.

No início do século XIX, quando naturalistas europeus percorreram a região, a exploração da floresta restringia-se à demanda de consumo de lenha para suprir os fornos das instalações de fundições de ferro.

Os naturalistas Spix e Martius viajaram pelo Brasil no período de 1817 à 1820 . Segundo relatos de SPIX (1981), a paisagem entre Sorocaba e Ipanema já apresentava características ambientais de transição com a fisionomia vegetal de mata sobre a serra de Araçoiaba.

(...) Esperamos em Sorocaba apenas a frescura da tarde, a fim de seguirmos para a Fábrica de São João do Ipanema. Passamos por campos com morros baixos, cobertos de capim rasteiro e de algumas árvores anãs por entre as quais se eleva, nas baixadas aqui e acolá, arvoredo cerrado e baixo, e alcançamos 
ao pôr do sol o lugarejo (...) lindos campos formam o primeiro plano, e a montanha de ferro de Arrasojava (Guarasojava), coberta de mato escuro, que desce pela encosta noroeste abaixo até o vale, constitui o fundo do cenário. (...) As matas virgens, que se ostentam mais densas e luxuosas nas baixadas do que nas regiões mais altas, possuem riqueza fora do comum, das mais diversas qualidades de madeira (...) perobas, jequitibás, cedros, etc..(...)

Nas descrições de SAINT-HILAIRE (1972), que passou por Ipanema pouco depois de Spix e Martius, reforçam-se as características e potenciais apresentadas por Spix; este naturalista acrescenta porém características às fisionomias vegetais que ocorriam na região de Ipanema que sugerem a presença também de cerrado:

(...) As terras são entremeadas de aprazíveis pastagens e capões de mato pouco elevado, onde predominam as myrtaceas, a aroeira, a bacharis tão comum, a que se dá o nome de alecrim dos campos etc.. (...) A 5 léguas de Itú, 252 27', aproximadamente, encontramos um campo, onde, em meio de ervas e sub-arbustos, elevam-se, umas bem juntas das outras, árvores definhadas, de casca suberosa, com folhas duras e quebradiças (...) Semelhantes campos (tabuleiros cobertos) existem também perto de Sorocaba (...) A algumas léguas também dessa vila, encontra-se, nos lugares pantanosos, (...) capões de mato, que ocupam sempre a parte mais baixa desses pântanos, formam, de ordinário, uma orla extensa, apresentando à vista um espesso conjunto de arbustos e de árvores de troncos frágeis e compridos, quase todos ramosos desde a base. (...) As pastagens, além das cercanias de Sorocaba, são entremeadas de capões de mato de uma extensão mais ou menos considerável; aquelas excelentes para a criação de gado, compõem-se, especialmente de gramíneas, e, nas mesmas, não só não crescem árvores, como, ainda vêem-se poucos sub-arbustos. (...)

Dos trabalhos de HUECK (1956), TROPPMAIR (1969), EITEN (1970) e VICTOR (1975), pôde-se concluir que o Estado de São Paulo, apresentava-se com $80 \%$ de sua área recobertos por florestas primitivas, sendo o restante ocupado por diversas fisionomias de Cerrado.

Com base no mapa do levantamento da cobertura vegetal primitiva do Estado de São Paulo realizado por TROPPMAIR (1969) pôde-se constatar que, para a região de Sorocaba e arredores, a vegetação primitiva seria composta por mata, cerrados e campos limpos.

Em seus estudos fitossociológicos realizados na área da FLONA, ALBUQUERQUE (1999) concluiu que a floresta atualmente encontrada no Morro de Araçoiba pode ser classificada como Floresta Estacional
Semidecídua, pois, entre outras características, ela apresenta muitas semelhanças com outras florestas do mesmo tipo no Estado de São Paulo.

Para BRASIL (1992), o conceito ecológico de Floresta Estacional Semidecídua está condicionado pela dupla estacionalidade climática, uma tropical com época de intensas chuvas de verão, seguida por estiagem acentuada e outra subtropical sem período seco, mas com seca fisiológica provocada pelo intenso frio do inverno, com temperaturas médias inferiores a $15^{\circ} \mathrm{C}$.

Considerando-se que o clima é o componente mais dinâmico da paisagem e que, por este motivo, não pode ser classificado de modo estanque e acrescentando-se o fato da FLONA se localizar em uma área de transição climática, conclui-se que as características climáticas relacionadas ao "conceito ecológico de Floresta Estacional Semidecidual” (BRASIL, 1992), apresentadas acima, estão de acordo com as caracterizações do clima para FLONA segundo SETZER (1944), MONTEIRO (1973) e ALBUQUERQUE (1999).

Sendo assim, com base nas diferentes descrições da cobertura vegetal primitiva e atual, bem como na caracterização do clima da região pode-se concluir, levando-se em consideração o conceito de clímax climático, que a vegetação potencial da FLONA de Ipanema, para a escala adotada para este trabalho, seria caracterizada como Floresta Estacional Semidecidual.

Importante lembrar que um trabalho mais minucioso de levantamento do clima (microclima) permitiria uma diversificação na potencialidade, como constata ALBUQUERQUE (1999):

A mata do Morro de Araçoiaba apresenta um mosaico ambiental e sucessional formado por áreas com características fitofisionômicas e edáficas distintas, sendo que a vegetação do sopé difere daquela existente no topo do Morro, possivelmente pelas diferentes intensidades de perturbações e pelo microclima que deve ser gerado pela própria formação do Morro.

Em se tratando do clímax edáfico, foram identificadas somente as áreas que poderiam sustentar florestas ou cerrado como vegetação potencial. Para as outras áreas, por se apresentarem muito modificadas devido ao diferentes usos desde o século XVI e, principalmente, nos últimos 40 anos, não foi possível uma correlação entre os diferentes tipos de solo, segundo RANZANI et al. (1965) e o uso atual para uma projeção da cobertura vegetal futura.

Portanto, o clímax edáfico de mata foi prognosticado para as áreas com:

- $\quad$ solos que, atualmente cobertos por florestas (mata ou capoeira), não apresentam, por este motivo, limitações para o aparecimento destas formações, entendendo-se que a 


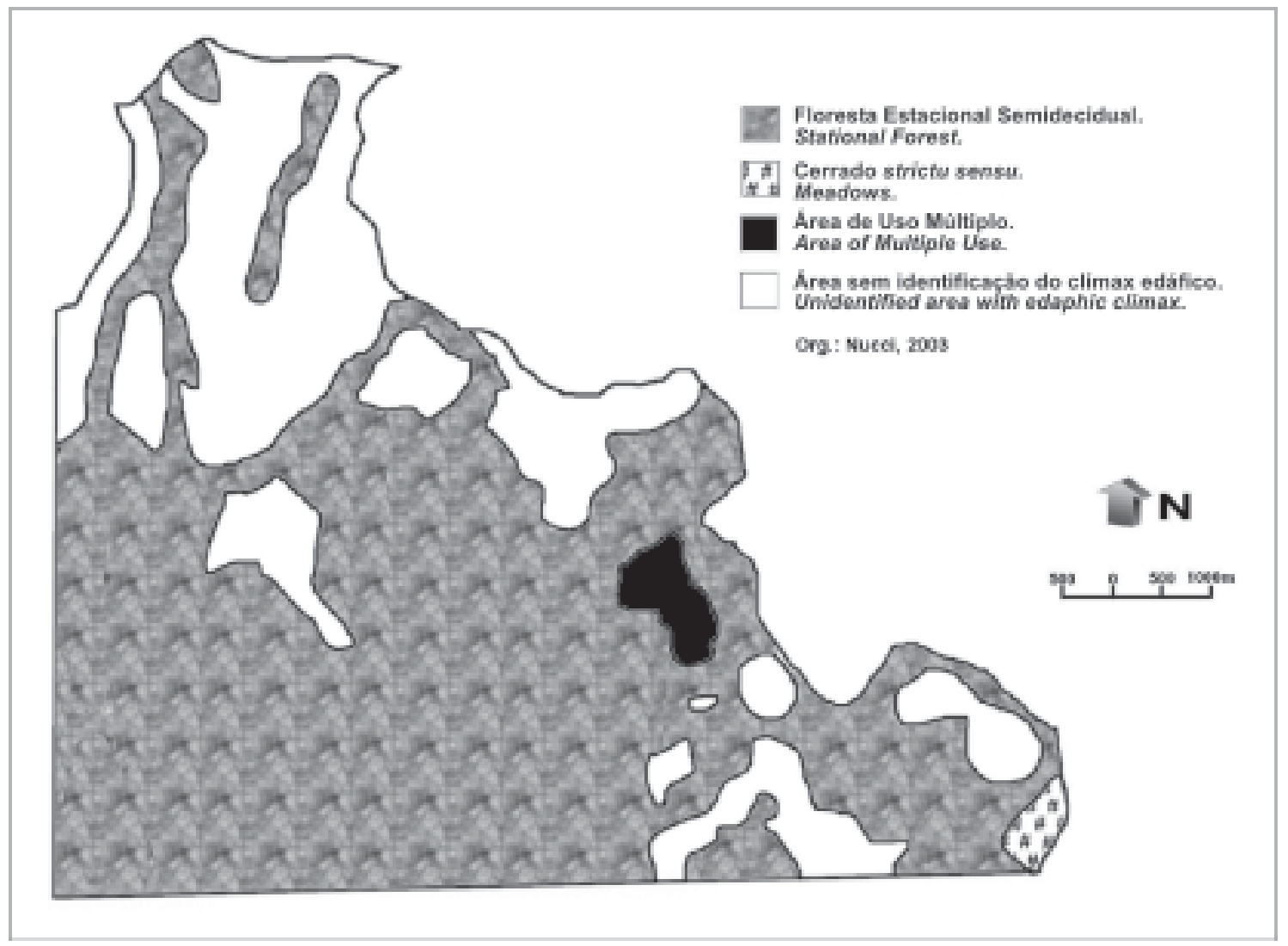

capoeira, em estágios inicial ou médio de regeneração, poderá apresentar com o tempo um maior desenvolvimento;

- $\quad$ solos hidromórficos que se localizam próximos aos rios e solos aluviais, associados aos hidromórficos porém em áreas mais elevadas do terreno, que poderiam sustentar formações florestais adaptadas às oscilações de nível do lençol freático (mata ciliar com ocorrência de brejos nas áreas permanentemente alagadas);

- $\quad$ exposições rochosas de arenito que se apresentam, atualmente, parte cobertas por mata e parte cobertas por campo; acreditase que o solo da área do alto da serra cortada pela estrada de acesso ao monumento histórico a Varnhagen e as torres de retransmissão, permitiria o desenvolvimento da mata mas que permanece como campo devido ao uso e às queimadas que se iniciam na área ocupada pelo MST e que, com o vento, acabam atingindo essa área da FLONA.
O clímax edáfico de Cerrado foi prognosticado para a área atualmente ocupada pela mancha de Cerrado sensu strictu que, mesmo sob um clima que permitiria a formação de uma Floresta Estacional Semidecídua, permanece como Cerrado graças às limitações provenientes do solo e, provavelmente, de fogo natural, acidental ou provocado intencionalmente. Sem as limitações das queimadas e dado um tempo no momento não previsível, essa comunidade de cerrado poderá aumentar, pouco a pouco, o conteúdo orgânico do solo havendo, conseqüentemente, uma melhoria em suas propriedades de retenção de umidade, estrutura e nível de toxicidade devido ao alumínio e, assim, finalmente, ceder lugar a uma floresta.

As áreas que atualmente estão ocupadas por reflorestamento, e que no passado também foram cultivadas e as áreas utilizadas pelo MST para uso agrícola e pastagem, certamente, não apresentam mais as características descritas por RANZANI et al. (1965), fato que dificulta a caracterização do clímax edáfico.

O fato da FLONA ter passado por testes agrícolas que modificaram a constituição física e química de seus 
solos impede uma explicação coerente, por exemplo, para o fato da existência de áreas que apesar de contarem com o mesmo tipo de solo, segundo RANZANI et al. (1965), se apresentam ocupadas uma com floresta (no pé da serra) e a outra com Cerrado sensu strictu.

É, também, muito difícil fazer qualquer previsão sobre a vegetação potencial nas áreas com mineração de calcário. Nos trabalhos de campo verificou-se que as diversas atividades relacionadas à mineração de calcário provocou uma grande alteração nas qualidades e até a total degradação dos solos.

Estudos sobre a regeneração de florestas constataram que as etapas de sucessão e o tempo necessário para a recomposição de uma área desmatada dependem de como a floresta foi removida, do tipo e do tempo de uso após a remoção, do tamanho da clareira artificial aberta, da densidade de gramíneas que funcionariam como competidoras e barreira para a germinação de sementes, da distância da floresta primária, das taxas de predação por insetos e mamíferos, da umidade do solo, da amplitude térmica, etc (UHL et al., 1982, apud SALOMÃO et al., 1998). SALDARRIAGA et al. (1988 apud SALOMÃO et al., 1998) estimaram que para as áreas agrícolas alcançarem área basal e biomassa semelhantes às de florestas maduras seriam necessários aproximadamente 190 anos.

Portanto, com base nos conceitos de clímax climático e clímaces edáficos conclui-se que a vegetação potencial da FLONA seria de Floresta Estacional Semidecidual com manchas das diversas fisionomias de Cerrado.

A figura 04 apresenta o croqui da vegetação potencial de Floresta Estacional Semidecidual (75\%) e de Cerrado (1\%), da área de Uso Múltiplo (1\%) e das áreas sem identificação do clímax edáfico (23\%), indicando a distribuição espacial e as porcentagens relativas como uma proposta de meta a ser alcançada na gestão da área.

\section{REFERÊNCIAS}

AB'SABER, A. N. Domínios morfoclimáticos e províncias fitogeográficas do Brasil. Orientação n. 3, Instituto de Geografia/USP, 1967, p. 45-48.

ALBUQUERQUE, G. B. Floresta Nacional de Ipanema: Caracterização da Vegetação em Dois Trechos Distintos do Morro de Araçoiaba, Iperó (SP). Piracicaba. Dissertação (Mestrado em Ciências Florestais) - ESALQ/USP, 1999, 186p.

BERTRAND, G. Paisagem e Geografia Física Global, Esboço Metodológico. São Paulo. Caderno de Ciências da Terra Revista do DG- FFLCH/USP, n.13, 1972, p. 1-27.

\section{CONSIDERAÇÕES FINAIS}

O mapeamento da vegetação e dos usos das terras são destacados como primordiais e indispensáveis para entendimento da dinâmica das paisagens e para orientar estratégias do plano de manejo.

O plano de manejo deve exercitar-se segundo normas de lei sendo importante considerar as normas legais como o Código Florestal brasileiro, o Decreto 750/ 93, as resoluções do CONAMA, entre outras, na classificação e mapeamento da cobertura vegetal como subsídio ao planejamento, procurando, se possível, uma adaptação aos termos mais utilizados pela comunidade local que deve participar do planejamento da área.

As categorias adotadas para legendar o Mapa da Vegetação e de Usos Atuais bem como as porcentagens relativas foram: Mata (35,7\%), Capoeira (16,9\%), Campo (11,0\%), Capoeira+Campo+Brejo (7,2\%), Cerrado sensu strictu (1,0\%), Reflorestamentos e Áreas cultivadas (5,7\%), Cultivos diversos+Pasto+Campo $(21,5 \%)$ e Área de uso múltiplo $(1,0 \%)$.

A caracterização da vegetação potencial é um exercício de diagnóstico da situação futura (prognose, prognóstico ou previsão), levando-se em conta as possibilidades de evolução natural a médio e a longo prazo, considerando-se, assim, a vegetação potencial um importante conceito para a conservação da natureza.

Conceitua-se vegetação potencial como a máxima expressão que a vegetação atingiria se tivesse a liberdade de se desenvolver sem a interferência do ser humano, considerando-se os atuais limites dados pelo clima e pelas condições edáficas.

Sugere-se como subsídio para o Plano de Manejo/ Gestão da FLONA de Ipanema a previsão de uma paisagem futura com a sua distribuição dada pelo croqui elaborado e as proporções da vegetação potencial de Floresta Estacional Semidecidual (75\%) e de Cerrado $(1 \%)$.

BRASIL. Constituição da República Federativa do Brasil. Brasília: DF. Senado, 1988.

BRASIL. Manual Técnico da Vegetação Brasileira. Rio de Janeiro. Série Manuais Técnicos em Geociências, n. 1, 1992, $92 \mathrm{p}$.

BRASIL. Mapa de Vegetação do Brasil, na escala 1:5.000.000, 1993.

BRASIL. Resolução CONAMA n. 001 de 31 de janeiro de 1994. Disponível em: <http://www. senado.org.br>. Acesso em: 21 ago 2000. 
FÁVERO, O. A. et al. Vegetação natural potencial e mapeamento da vegetação...

BRASIL. LEI no. 9.985, de 18 de julho de 2000. Institui o Sistema Nacional de Unidades de Conservação do Brasil (SNUC). Disponível em: <http://www. senado.org.br>. Acesso em: 21 ago 2000.

EITEN, G. A Vegetação do Estado de São Paulo. São Paulo. Boletim do Instituto de Botânica, v. 7, 1970.

FÁVERO, O. A. Do Berço da Siderurgia Brasileira à Conservação de Recursos Naturais - Um Estudo da Paisagem da Floresta Nacional de Ipanema (Iperó/SP). São Paulo. Dissertação (Mestrado em Ciências - Geografia Humana) - DG/ FFLCH/USP, 2001, 257p.

GÓMEZ OREA, D. El Medio Fisico y la Planificación. Madrid. Cuadernos del CIFCA. (v. 1 e v. 2), 1978.

HUECK, K. Mapa fitogeográfico do Estado de São Paulo. São Paulo. Boletim Paulista de Geografia, n. 22, 1956, p. 19-25.

McHARG, I. L. Design with Nature. New York. Paperback edition. The American Museum of Natural History, 1971, 198p.

MICHALSKI, F. Ecologia de Carnívoros em Área Alterada no Sudeste do Brasil. Porto Alegre. Dissertação (Mestrado em Ciências Biológicas) - Instituto de Biociências, Universidade Federal do Rio Grande do Sul, 2000, 98p.

MONTEIRO, C. A. de F. A Dinâmica Climática e as Chuvas no Estado de São Paulo. São Paulo: IGEOG/USP, 1973, 129p. (Estudo geográfico sob forma de atlas).

MONTEIRO, C. A. de F. Geossistemas: a História de uma Procura. São Paulo: Contexto, 2000, 127p.

NAVEH, Z.; LIEBERMAN, A.S. Landscape Ecology. Theory and Application. New York: Spring-Verlag, 1983.

NUCCI, J. C. Qualidade Ambiental e Adensamento Urbano. São Paulo: HUMANITAS/FAPESP, 2001, 236p.

ODUM, E. P. Ecologia. Rio de Janeiro: Discos CBS (Interamericana), 1985, 434p.

RANZANI, G.et al. Carta de Solos da Fazenda Ipanema. Piracicaba. PROJETO ETA-70 (Ministério da Agricultura/Escritório Técnico da Agricultura/ESALQ-USP), 1965, 52p.
REGALADO, L. B. Composição e Distribuição de Aves Passeriformes em uma Parcela de Mata do Morro de Araçoiaba (Floresta Nacional de Ipanema - Iperó/SP) Utilizando um Sistema de Informações Geográficas São Carlos. Dissertação (Mestrado em Ciências da Engenharia Ambiental) - Escola de Engenharia, Universidade Federal de São Carlos, 1999, 118p.

RIZZINI, C. T. Tratado de Fitogeografia do Brasil. São Paulo: EDUSP/HUCITEC, 1963, 374p.

SAINT-HILAIRE, A. Viagem à Província de São Paulo e Resumos das Viagens ao Brasil, Província Cisplatina e Missões do Paraguay. São Paulo: Martins Fontes/EDUSP, 1972.

SALOMÃO, R. de P.; NEPSTAD, D. C.; VIEIRA, I. C. G.. Biomassa e estoque de carbono de florestas tropicais primária e secundária. In: GASCON, C.; MOUTINHO, P. (Eds.) Floresta Amazônica: dinâmica, regeneração e manejo. Manaus: INPA, 1998, 373p.

SECRETARIA DE ESTADO DO MEIO AMBIENTE, COORDENADORIA DE INFORMAÇÕES TÉCNICAS, DOCUMENTAÇÃO E PESQUISA AMBIENTAL, INSTITUTO FLORESTAL (SMA/CINP/IF). Inventário Florestal do Estado de São Paulo. São Paulo: IF, 1993, 198p. il.

SETZER, J. O Clima do Estado de São Paulo. Rio de Janeiro: IBGE, Boletim Geográfico, n. 19, 1944.

SPIX, J. B. Viagem pelo Brasil: 1817-1820/Spix e Martius. Belo Horizonte: Ed. Itatiaia. São Paulo: EDUSP. (Coleção Reconquista do Brasil; nova sér.; v. 46, 1981.

TAVARES, R. O Clima Local de Sorocaba (SP): Tendências e Análise Comparativa Cidade - Campo. São Paulo. Dissertação (Mestrado em Ciências - Geografia Humana) - DG/ FFLCH/USP, 1997.

TROPPMAIR, H. A cobertura vegetal primitiva do Estado de São Paulo. Biogeografia, n. 1, Instituto de Geografia/USP, 1969, p. 1-11.

VITOR, M. A. M. A Devastação Florestal. São Paulo. Rev. da Sociedade Brasileira de Silvicultura, 1975, 48p. 